\title{
Effectiveness of Endoscopic Third Ventriculostomy in Obstructive Hydrocephalus of Different Etiology in Terms of Reduction of Ventricle Diameter
}

\author{
Hamayun Tahir ${ }^{1}$, Muhammad Ayaz, Mumtaz Ali ${ }^{3}$, Naseer Hassan ${ }^{4}$, Syed Nasir Shah ${ }^{5}$, \\ Samina Feroz ${ }^{6}$
}

\section{ABSTRACT}

Background: Endoscopic techniques are now gaining insight into the management of various neurosurgical pathologies, including Endoscopic third ventriculostomy (ETV), which is a well-accepted technique for obstructive hydrocephalus of various etiologies.

Objective: To determine the effectiveness of endoscopic third ventriculostomy in obstructive hydrocephalus in terms of reduction of third ventricle diameter (width).

Material and Method: This descriptive case series study was conducted at the Department of Neuro Surgery, Lady Reading Hospital, from January 2019 to December 2020. A total of 195 patients between age 1- 60 years meeting the inclusion criteria underwent endoscopic third ventriculostomy by a single expert neurosurgeon. Effectiveness of endoscopic third ventriculostomy was measured to reduce at least $1 \mathrm{~mm}$ or more from the baseline third ventricle diameter (width) after two months of surgery.

Results: In our study, 127 (65.12\%) patients were male, while $68(34.87 \%)$ were Females. Mean, and S.D. forAge was as 30.05 Years +17.46 . The Mean Baseline 3rd Ventricle Diameter was $5.218 \mathrm{~mm}+1.1$, whereas on $60^{\text {th }}$ postoperative Day Follow Up, the mean 3 rd Ventricle Diameter was recorded as $4.35 \mathrm{~mm} \pm 1.25$. The difference in means between the two groups was 0.864 ( $p$ value $<0.0001$ ), which is statistically significant. Effectiveness of Endoscopic Third Ventriculostomy was recorded on 105 (53.84\%) patients, whereas in 90 (46.15\%) patients, Obstructive Hydrocephalus remained unchanged.

Conclusion: Calculated volumetric measurements (e.g., width) from C.T. scans after successful third ventriculostomy can display a demonstrable reduction in ventricular volume and help evaluate patients postoperatively.

Keywords: ETV, Hydrocephalus, stereotactic.

This article may be cited as: Tahir H, Ayaz M, Ali M, Hassan N, Shah SN, Feroz S. Effectiveness of Endoscopic Third Ventriculostomy in Obstructive Hydrocephalus of Different Etiology in Terms of Reduction of Ventricle Diameter . J Saidu Med Coll Swat. 2021;11(4):185-90.DOl:https://doi.org/10.52206/jsmc.2021.11.4.676

\section{INTRODUCTION}

In recent times, endoscopic strategies have indeed been widely used to manage multiple neurosurgical pathologies ${ }^{1-3}$. Endoscopic third ventriculostomy (ETV) for obstructive hydrocephalus treatment with different aetiologies is well known ${ }^{4}$. In post-hemorrhagic, postinfectious causes of hydrocephalus, ETV's chance of success is low; however, it is safe in adequately selected situations. Good preoperative preparation, supportive imaging, surgeon expertise, and appropriate postoperative treatment serves to improve outcomes.

1. Department of Neurosurgery, Qazi Hussain Ahmad Medical Complex, Nowshera Medical College Nowshera MTI kpk.

2. Department of Neurosurgery, Prime Teaching Hospital,

Peshawar Medical College/Irfan General Hospital Peshawar.

3. Department of Neurosurgery, Qazi Hussain Ahmad Medical Complex, Nowshera Medical College Nowshera MTI kpk.

4. Department of Neurosurgery, Saidu Teaching Hospital,

Saidu Medical College Swat.

5. Department of Neurosurgery, DHQ Hospital Mardan.

6. Gandhara University, Kabir Medical College Peshawar.

Correspondence: Dr. Hamayun Tahir (MBBS, FCPS Neurosurgery)

Senior Registrar Neurosurgery,

Department of Neurosurgery Qazi Hussain Ahmed Medical Complex

(MTI) Nowshera /Nowshera Medical College Nowshera

Email:hamayun_tahir@ymail.com
Obstructive hydrocephalus is originated as a result of blockage of cerebrospinal fluid (CSF) circulation. Obstructive hydrocephalus is clinically caused by diseases that cause occlusion in the Ventricular system and is often referred to as noncommunicating hydrocephalus. For decades, obstructive hydrocephalus management has progressed from Dandy and Mixter's first insight with an endoscopic attitude, through shunting initiated by Spitz \& Nulsen, to today's highly valued endoscopic third ventriculostomy (ETV) ${ }^{5}$. An endoscopic third ventriculostomy is an ingrained form of care in pediatric neurosurgery, enabling shunt placements to be minimized. At the same time, adults have fewer reports on this topic ${ }^{6}$. There seems to be no convincing, straightforward diagnostic approach that enables patients to be selected appropriately for ETV. Hypothetically, the most impressive efficacy of ETV should indeed be obtained in cases of obstructive hydrocephalus with retained subarachnoid space patency, up to the extent of CSF absorption. In reality, however, the ETV certification is mostly based on scientific standards. Over time, due to technical advancements in stereotactic driven processes and now both mechanical and optical modulations, there seems to be a revival in adopting ETV as the ideal method for the 
management of obstructive hydrocephalus in patients treated worldwide ${ }^{7-9}$. However, much of the available studies on this argument came from industrialized countries with developed healthcare facilities. The present research is intended to determine the endoscopic third ventriculostomy's effectiveness in obstructive hydrocephalus of various etiologies in reducing the third ventricle's diameter. This type of study has not yet been conducted in our local people, which seem to be a neglected area. This research will give us the local extent of the issue and new regional statistics. This study will be matched with globally published literature, and we will share the results of this study with other local neurosurgeons if it is found to be substantially high. We will recommend not only further studies but also required modifications in management and principles.

\section{MATERIALS AND METHODS}

This descriptive case series study was conducted at the Department of Neuro Surgery, Lady Reading Hospital PGMI Peshawar, from January 2019 to December 2020. A total of 195 patients, through non-probability consecutive sampling, taking the proportion of total reduction of ventricular diameter $54.2 \%{ }^{9}$, keeping confidence level $95 \%$ \& margin of error $7 \%$ under $\mathrm{WHO}$ formula for sample size, meeting inclusion criteria were enrolled in the study.

\section{Inclusion Criteria}

1) All the patients with a diagnosis of obstructive hydrocephalus, i.e., C.T. brain showing temporal horns of more than $2 \mathrm{~mm}$ (normally barely visible), Evan's ratio of greater than $30 \%$ (ratio of the width of frontal horns to the axial diameter, i.e., the biparietal diameter of a cranial cavity) and ballooning of the third ventricle and frontal horns of the lateral ventricle.

2)Age 1-60 years.

3) Patients of either sex.

\section{Exclusion Criteria}

1) Patients with severe comorbidities that can affect morbidity and mortality.

2) Patients with a lesion in the third ventricle or its floor or near a basilar artery, diagnosed by computerized tomography scan. (Causes difficulty in perforation)

3) Patients with third ventricular size less than seven millimeters, diagnosed by Computerised tomographic scan
4)

\begin{abstract}
Patients with recurrent hydrocephalus who have undergone V.P. Shunt or patients in whom aetiology was determined as subarachnoid hemorrhage, communicating hydrocephalous, or postinfectious hydrocephalus were removed from this study.
\end{abstract}

\section{Data Collection Procedure}

The research was performed after approval from the hospital's ethical \& research committee(Ref.No.1071/Dy/REG/PGMI, Dated:1/1/2019). All consecutive patients meeting the inclusion criteria with the diagnosis of obstructive hydrocephalus were enrolled in the study through outpatient or emergency department and was admitted to neurosurgery ward for further workup including detailed history followed by complete physical, neurological, and radiological examination( i-e C.T. scan thin cuts ) and the standard set of investigations. The study's purpose and benefits were clarified to the patients and informed written consent was obtained. The enrolled patients were put on the O.T. list for the next O.T. day after performing the anesthesia assessment through an expert anesthesiologist. On the next O.T. day, Under general anesthesia, an endoscopic third ventriculostomy was carried out by a single expert neurosurgeon having a minimum of 5 years of experience.

\section{Operative Technique}

All patients were properly hydrated before surgery, and Intravenous antibiotics were administered. Patients were placed in a supine position following intubation with their head flexed. At the right side, anterior to the coronal suture, a burr hole was mounted just about $2.53 \mathrm{~cm}$ lateral to the midline, i.e., at Kocher's point. The assembled endoscope, then guided thru the foramen of Monro under direct vision, and a blunt fenestration of about $5 \mathrm{~mm}$ was made in the thinnest portion of the third ventricular floor between the infundibular recess and mammillary bodies at the most transparent region to prevent injuries and intraoperative bleeding. The ventriculostomy made was then dilated using the Fogarty catheter. Direct endoscopic basal artery visualisation confirmed sufficient fenestration. When the endoscope was retracted again into the third ventricle, the CSF passed between the third ventricle and the basal cistern, and the fenestration edges were seen going up and down. In case of any haemorrhage, plentiful warm Normal saline irrigation was used until entirely bleeding ended and the ventricular CSF becomes clear. 


\section{Followup \& Outcome Valuation}

The patients were followed up till 2 months postoperatively. All the valuable information, including demographics, aetiology, baseline, and Postoperative $60^{\text {th }}$-day third ventricle diameter using thin cuts CTscan, were recorded in a predesigned Performa prospectively. Effectiveness of endoscopic third ventriculostomy was measured to reduce at least $1 \mathrm{~mm}$ or more from the baseline ventricle diameters after twomonth surgery on thin cuts C.T. scan. To control confounders and bias in the study results, strict exclusion criteria were followed.

\section{Data Analysis}

The data was entered, stored, and analysed in IBM SPSS statistics 20. Descriptive statistics, e.g., Mean + S.D., were calculated for quantitative variables like age, baseline third ventricle diameter, and Postoperative $60^{\text {th }}$-day third ventricle diameter. Frequencies and percentages were calculated for categorical variables like gender, aetiology, and effectiveness. Effect modifiers like age, gender, and aetiology were dealt with through stratification to see their effects on the outcome. Chi-square test was applied after stratification keeping $p$-value $=0.05$ as significant

\section{RESULTS}

Out of 195 patients, 127 (65.12\%) patients were male while $68(34.87 \%)$ were females Mean and SD for Age was as 30.05 Years \pm 17.46 . . The Mean Baseline 3rd Ventricle Diameter was $5.218 \mathrm{~mm} \pm 1.1$, whereas on $60^{\text {th }}$ postoperative Day Follow Up, the mean 3rd Ventricle Diameter was recorded as $4.35 \mathrm{~mm} \pm 1.25$. The difference in means between the two groups was 0.864 ( $p$ value<0.0001) (Table No. 1).
Effectiveness of Endoscopic Third Ventriculostomy on Obstructive Hydrocephalus was recorded on 105 (53.84\%) patients with whereas, in 90 (46.15\%) patients, Obstructive Hydrocephalus remained unchanged (Table No. 2).

In the Age Group of 1-20 Years, 65 (33.33\%) patients were recorded. In the Age Group of 21-40 Years, 68 (34.87\%) were recorded. In the Age Group of 41-60 Years, 62 (31.79\%) patients were recorded. As per Etiology of the Obstructive Hydropecphalus in studied patients, 90 (46.15\%) patients were having Primary Aqueductal Stenosis, $53(27.17 \%)$ patients had Cerebellopontine Angle Tumor, 38 (19.48\%) were having Cerebellar Tumor \& posterior fossa tumors, $14(7.17 \%)$ patients were having other tumors (benign cyst, mesencephalic tumors, posterior third ventricular tumors)

Post-stratification of Endoscopic Third Ventriculostomy effectiveness in reducing Ventricle Diameters concerning Age and Gender can be seen in Table No. 3). The highest success rate was recorded for Obstructive hydrocephalus due to aqueductal stenosis $(25.12 \%)$, followed by C.P. angle tumors $(17.43 \%)$ and the least in cases of other tumors $(2.56 \%)$. There was, however, no statistically significant correlation in our case series between etiology and outcomes ( $p$-value = 0.573). Similarly, a statistically significant correlation between gender and outcomes was not identified $(p$-value $=0.2755)$.

Table No.1: Efficacy of ETV Concerning Etiology

\begin{tabular}{|l|l|l|}
\hline \multirow{2}{*}{ CAUSE OF HYDROCEPHALUS } & \multicolumn{2}{|c|}{ EFFICACY } \\
\cline { 2 - 3 } & \multicolumn{1}{|c|}{ YES } & \multicolumn{1}{c|}{ NO } \\
\hline Primary aqueductal stenosis & $49(25.12 \%)$ & $41(21.02 \%)$ \\
\hline Cerebellopontine angle tumor & $34(17.43 \%)$ & $19(9.74 \%)$ \\
\hline Cerebellar tumor \& posterior fossa tumours & $17(8.71 \%)$ & $21(10.76 \%)$ \\
\hline Other tumours & $5(2.56 \%)$ & $09(4.61 \%)$ \\
\hline Total & $\mathbf{1 0 5}(\mathbf{5 3 . 8 4} \%)$ & $\mathbf{9 0}(\mathbf{4 6 . 1 5 \% )}$ \\
\hline
\end{tabular}


Table No. 2: Stratification of Efficacy of Etv for age :(n=195)

\begin{tabular}{|c|c|c|c|c|}
\hline AGE & EFFICACY & FREQUENCIES & PERCENTAGES & P VALUE \\
\hline & Yes & 33 & $16.92 \%$ & \multirow{9}{*}{0.001} \\
\hline 1-20 Years & No & 32 & $16.41 \%$ & \\
\hline \multicolumn{2}{|l|}{ Total } & 65 & $33.33 \%$ & \\
\hline & Yes & 48 & $24.61 \%$ & \\
\hline $21-40$ Years & No & 20 & $10.25 \%$ & \\
\hline \multicolumn{2}{|l|}{ Total } & 68 & $34.87 \%$ & \\
\hline & Yes & 24 & $12.30 \%$ & \\
\hline 41-60 Years & No & 38 & $19.48 \%$ & \\
\hline \multicolumn{2}{|l|}{ Total } & 62 & $31.79 \%$ & \\
\hline
\end{tabular}

Table No. 3: Stratification of Efficacy of Etv for Gender ( $n=195)$

\begin{tabular}{|c|c|c|c|c|}
\hline GENDER & EFFICACY & FREQUENCIES & PERCENTAGES & P VALUE \\
\hline \multirow{2}{*}{ Male } & Yes & 72 & $36.92 \%$ & \multirow{6}{*}{0.275} \\
\hline & No & 55 & $28.20 \%$ & \\
\hline Total & & 127 & $65.12 \%$ & \\
\hline \multirow{2}{*}{ Female } & Yes & 33 & $16.92 \%$ & \\
\hline & No & 35 & $17.84 \%$ & \\
\hline \multicolumn{2}{|l|}{ Total } & 68 & $34.87 \%$ & \\
\hline
\end{tabular}

\section{DISCUSSION}

In the developed world, endoscopic third ventriculostomy is the most widely done neuroendoscopic technique these days. ${ }^{10}$. It enables the restoration of CSF circulation conditions close to physiological and avoids shunt-related complications in many patients ${ }^{11,12}$. Even though the ETV procedure has been regularly practiced in many centers for many years in treating obstructive hydrocephalus, there are still issues of concern relating to the appropriate case selection, the operative methodology, and the evaluation of the efficacy of the treatment ${ }^{13-15}$. In experienced hands, the procedure is safe with minor complications as reported in the literature ${ }^{16}$

In literature, the recorded success rate of ETV is generally 6091.5 per cent ${ }^{15,17-20}$. Radiological change in the ventricle size can be correlated correctly with ETV success and can depict effectiveness ${ }^{21}$. At the same time, clinical and radiological presentation possibly helped us exclude impaired subarachnoid space patency and impaired resorption of CSF. To standardize the collected data following the other research, these requirements were adopted ${ }^{22,23}$. Schwartz et al. concluded that measuring the third ventricle's width is more important than the lateral ventricles for an accurate evaluation of ventriculostomy efficacy. In all reasonable cases, a decrease in the third ventricular diameter of at least 15 percent was seen, and none of the failures ${ }^{24}$. Our series showed a mean difference of 0.864 ( $p$ value $<0.0001$ ) when compared baseline third ventricular diameter with a post-op third ventricular diameter, which is statistically significant

In our series, the patients scheduled to undergo ETV surgery suffered from uncomplicated 
triventricular hydrocephalus, mainly due to primary aqueductal stenosis $(46.15 \%)$, rest to other space-occupying brain lesions. Endoscopic third ventriculostomy effectiveness in Obstructive Hydrocephalus was recorded on 105 (53.84\%) patients, whereas, in $90(46.15 \%)$ patients, hydrocephalus remained unchanged. The maximum effectiveness was for obstructive hydrocephalus secondary to stenosis of the aqueduct $(25.12 \%)$, followed by C.P. angle tumors $(17.43 \%)$. The outcomes of 100 consecutive procedures accomplished in 95 patients were analysed by Hopf et al. and concluded that ETV is utmost successful in managing uncomplicated obstructive hydrocephalus induced by aqueductal stenosis and other space-occupying brain tumors ${ }^{25}$. Our data support these arguments because, in patients having aqueductal stenosis and other space-occupying brain tumors, we were capable of achieving a reasonable result (53.84 percent); however, in our case series, there was no statistically significant correlation between aetiology and outcomes ( $p$-value $=0.573$ ). With an average age of 30.05 years +17.46 , most of our study patients were older than 34 years, and 65.12 percent were male. This pattern is close to other literature studies ${ }^{15,26}$. A statistically meaningful correlation between gender and outcomes ( $p$ value $=0.275$ ) was not found, however.

\section{CONCLUSION}

Endoscopic third ventriculostomy proved to treat obstructive hydrocephalus of both primary and secondary origin effectively. Calculated volumetric measurements (e.g., width) from thin cuts C.T. scans after active third ventriculostomy can display a demonstrable reduction in ventricular volume and help evaluate patients postoperatively.

\section{REFERENCES}

1. Katsuki M, Kakizawa Y, Nishikawa A, Yamamoto Y, Uchiyama T. Endoscopic hematoma removal of supratentorial intracerebral hemorrhage under local anesthesia reduces operative time compared to craniotomy. Sci Rep. 2020;10(1):103-89.

2. Chen D, Zhang J, Wu L, Li X, Ma S, Zhu X, et al. Neuroendoscopic treatment of multiple intracranial arachnoid cysts: a case report. Chinese Neurosurg J. 2018;4(1):19-25.

3. Yu Y, Hu F, Zhang X, Sun C. Endoscopic Transnasal Odontoidectomy. Sports Med Arthrosc. 2016 Mar;24(1):26-31.

4. Kontojannis V, Papadopoulos E, Ydreos J, Isaakidis D, Gavra MM, Boviatsis EJ. Endoscopic Third Ventriculostomy: A Single-Center Experience in Greece. Surg J (New York, NY). 2020 May 7;6(2):e716.
5. Stachura K, Libionka W. An outline of the history of neuroendoscopy. Przegl Lek. 2007;64(2):118-20.

6. Barszcz S, Roszkowski M, Drabik K, Turkowski Z, Kościesza A. Preliminary results of the treatment of occlusive hydrocephalus in children by endoscopic techniques. Neurol Neurochir Pol. 1998;32(1):73-82.

7. Ullah MA, Khan FU, Usman M, Ishaq M, Khan Z Frequency and Pattern of Early Complications after Endoscopic Third Ventriculostomy in Obstructive Hydrocephalus. Pakistan J Neurol Surg. 2020;24(3):237-42.

8. Wang $Q$, Cheng J, Zhang S, Li Q, Hui X, Ju Y. Prediction of endoscopic third ventriculostomy (ETV) success with pre-operative third ventricle floor bowing (TVFB): a supplement to ETV success score. Neurosurg Rev. 2020;43(6):1575-81.

9. Stachura K, Grzywna E, Kwinta BM, Moskała MM. Endoscopic third ventriculostomy - effectiveness of the procedure for obstructive hydrocephalus with different etiology in adults. Wideochirurgia i inne Tech maloinwazyjne $=$ Videosurgery other miniinvasive Tech. 2014/10/16. 2014 Dec;9(4):586-95.

10. Munda M, Spazzapan P, Bosnjak R, Velnar T. Endoscopic third ventriculostomy in obstructive hydrocephalus: A case report and analysis of operative technique. World J Clin cases. $2020 \mathrm{Jul}$ 26;8(14):3039-49.

11. Drake JM, Kulkarni A V, Kestle J. Endoscopic third ventriculostomy versus ventriculoperitoneal shunt in pediatric patients: a decision analysis. Child's Nerv Syst. 2009;25(4):467-73.

12. Bouras T, Sgouros S. Complications of endoscopic third ventriculostomy: a systematic review. In: Hydrocephalus. Springer; 2012. p. 149-53.

13. Brockmeyer D, Abtin K, Carey L, Walker ML. Endoscopic third ventriculostomy: an outcome analysis. Pediatr Neurosurg. 1998;28(5):236-40.

14. Hoppe-Hirsch E, Laroussinie F, Brunet L, SainteRose C, Renier D, Cinalli G, et al. Late outcome of the surgical treatment of hydrocephalus. Child's Nerv Syst. 1998;14(3):97-9.

15. Feng $\mathrm{H}$, Huang $\mathrm{G}$, Liao X, Fu K, Tan $\mathrm{H}, \mathrm{Pu} \mathrm{H}$, et al. Endoscopic third ventriculostomy in the management of obstructive hydrocephalus: an outcome analysis. J Neurosurg. 100(4):626-33.

16. Hader WJ, Walker RL, Myles ST, Hamilton M. Complications of endoscopic third ventriculostomy in previously shunted patients. Neurosurgery. 2008 Jul;63(1 Suppl 1):ONS168-74; discussion ONS174-5.

17. Gangemi M, Mascari C, Maiuri F, Godano U, Donati P, Longatti PL. Long-term outcome of endoscopic third ventriculostomy in obstructive hydrocephalus. min-Minimally Invasive Neurosurg. 2007;50(05):265-9.

18. Yadav YR, Mukerji G, Parihar V, Sinha M, Pandey S. Complex hydrocephalus (combination of communicating and obstructive type): an important cause of failed endoscopic third ventriculostomy. BMC Res Notes. 2009;2(1):137-41.

19. Choi JU, Kim DS, Kim SH. Endoscopic surgery for obstructive hydrocephalus. Yonsei Med J. 1999 Dec;40(6):600-7.

20. MohAnty Aa, SAntoSh Va, Devi BI, SAtiSh Sa, BiSwAS A. Efficacy of simultaneous single-trajectory endoscopic tumor biopsy and endoscopic cerebrospinal fluid diversion procedures in intra - and paraventricular tumors. Neurosurg Focus. 2011;30(4):E4. 
21. Naftel RP, Reed GT, Kulkarni A V, Wellons JC. Evaluating the Children's Hospital of Alabama endoscopic third ventriculostomy experience using the Endoscopic Third Ventriculostomy Success Score: an external validation study. J NeurosurgPediatr. 2011 Nov;8(5):494-501.

22. Amini A, Schmidt RH. Endoscopic third ventriculostomy in adult patients. Neurosurg Focus.2005;19(6):E9.

23. Tisell $M$, Almström $O$, Stephensen $H$, Tullberg $M$, Wikkelsö C. How effective is endoscopic third ventriculostomy in treating adult hydrocephalus caused by primary aqueductal stenosis? Neurosurgery. 2000 Jan;46(1):10-14.

24. Schwartz TH, Yoon SS, Cutruzzola FW, Goodman RR. Third ventriculostomy: postoperative ventricular size and outcome. min-Minimally Invasive Neurosurg. 1996;39(04):122-9.

25. Hopf NJ, Grunert P, Fries G, Resch KDM, Perneczky A. Endoscopic third ventriculostomy: outcome analysis of 100 consecutive procedures. Neurosurgery. 1999;44(4):795-804.

26. Brohi SR, Brohi AR, Sidiqui MA, Mughal SA, Saeed S. Outcome of endoscopic third ventriculostomy in hydrocephalus. J Surg Pak. 2010;15(1):25-8.
DATA SHARING STATEMENT: The data that support the findings of this study are available on request from the corresponding author. The data are not publicly available due to privacy or ethical restrictions.

CONFLICT OF INTEREST: Authors declared no conflict of interest.

GRANTED SUPPORT AND FINANCIAL DISCLOSURE: Nil

\section{AUTHOR'S CONTRIBUTION}

Following authors have made substantial contributions to the manuscript as under

Tahir H, Ayaz M:

Concept and design of study, Collection of data, statistical analysis

Ali M, Hassan N: Writing of manuscript, critical review of manuscript

Shah SN: Analysis and interpretation of data, statistical analysis

Feroz S: Data collection, bibliography

Authors agree to be accountable for all aspects of the work in ensuring that questions related to the accuracy or integrity of any part of the work are appropriately investigated and resolved. 